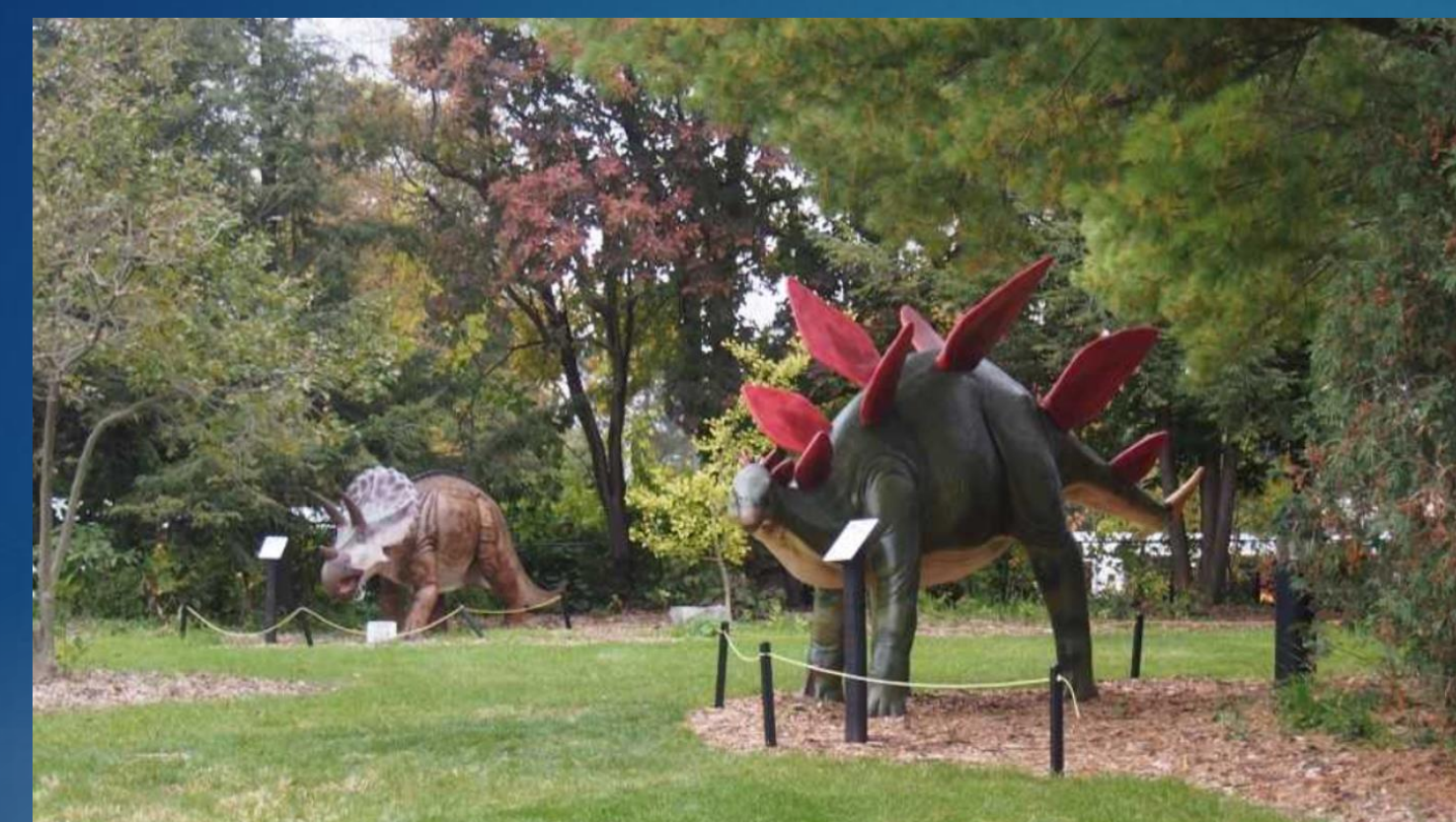

A. Caruthers, R. Gillespie, P. Voice WMU Department of Geological and Environmental Sciences

\title{
Dinosaur Park: The Multi-purpose Geological Platform at Western Michigan University
}


Dinosaurs Have Captured the Imagination of the Public for Close to Two Centuries

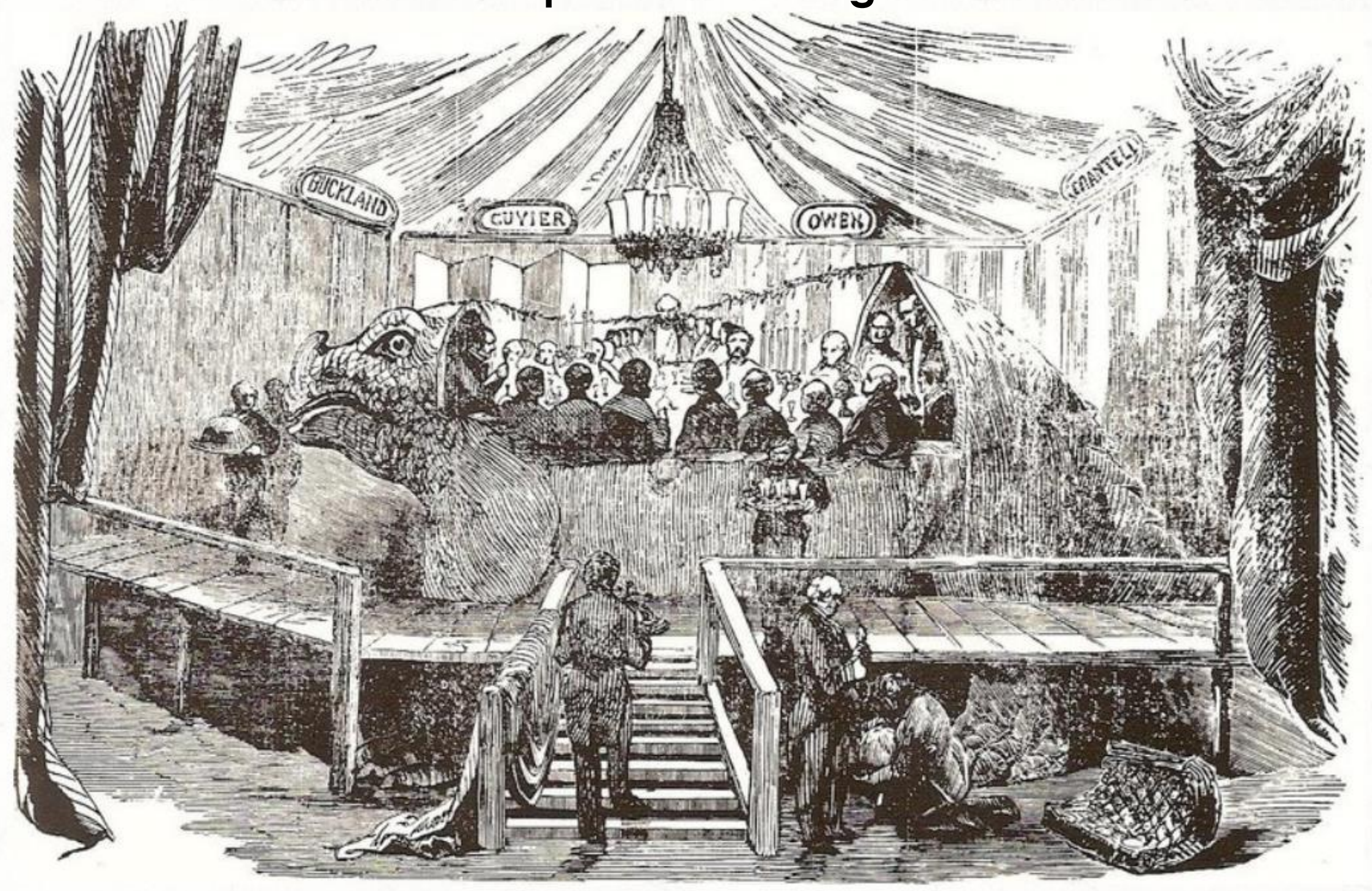

NEW YEAR'S EVE - 1853

A group of scientists, businessmen, and newspapermen sat down to dinner inside a life-sized iguanodon model. It was one of the first reconstructions of a dinosaur ever made, and the dinner was a publicity stunt that helped launch an incredibly successful craze: our obsession with dinosaurs.

Even the word "dinosaur" was new-invented by one of the dinner's attendees in 1842;

Richard Owen was a

The guests enjoyed a fabulous dinner in and around the iguanodon. THE LONDON ILLUSTRATED NEWS/PUBLIC DOMAIN

paleontology pioneer and the dinner's guest of honor. 


\section{Our Integrated Outreach Platform}

- On-campus - the Lloyd Schmaltz Geology and Mineral Museum and Rock Garden - tours - now includes Dinosaur Park

- Michigan Geological Repository for Research and Education - offcampus home of the Michigan Geological Survey - tours, professional training (teachers workshops and professional geologists workshops)

- CoreKids program - external outreach activities - school visits, booths at allied partner events (other Museums, mineral shows, etc.)

- Developing integrated approach - outreach on and off campus

- Reaches 20,000+ people per year-K-13 students, teachers, parents, professionals

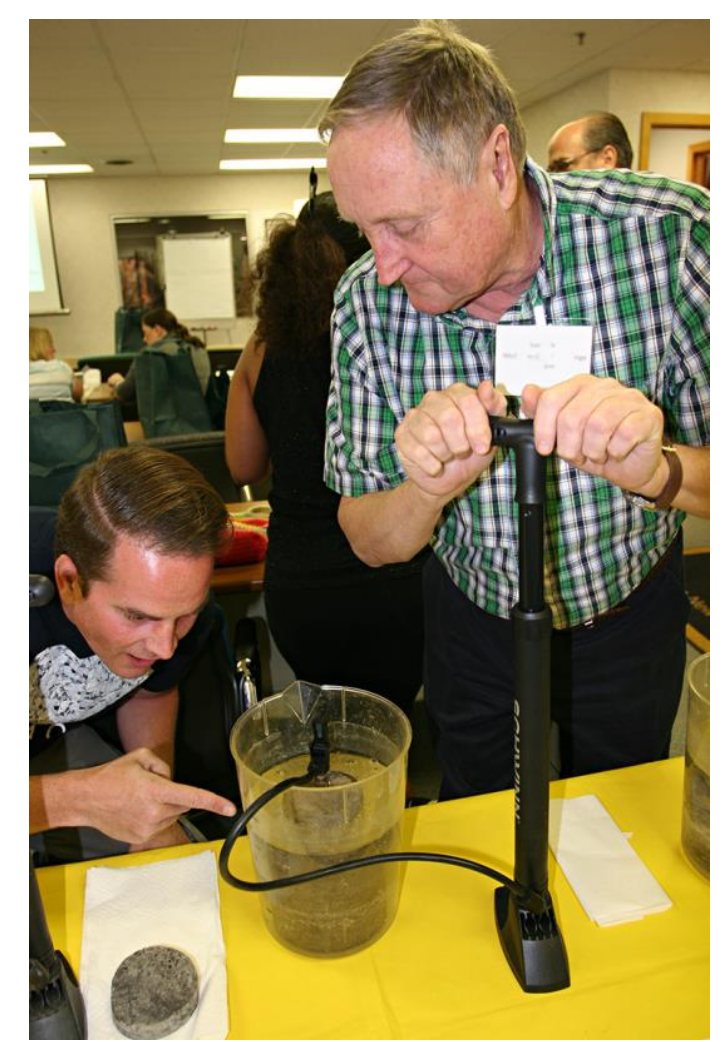

Teachers at a MGRRE-hosted workshop exploring rock porosity and permeability. 
Topics:

-Geology and Geologists

-Michigan Geology and Natural Resources

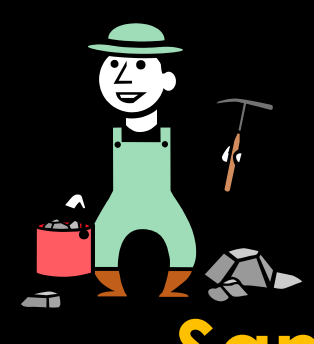

-Rocks and Minerals

-Water Resources

-Petroleum Geology

-Sands, Beaches and Coastlines

-Climate Change

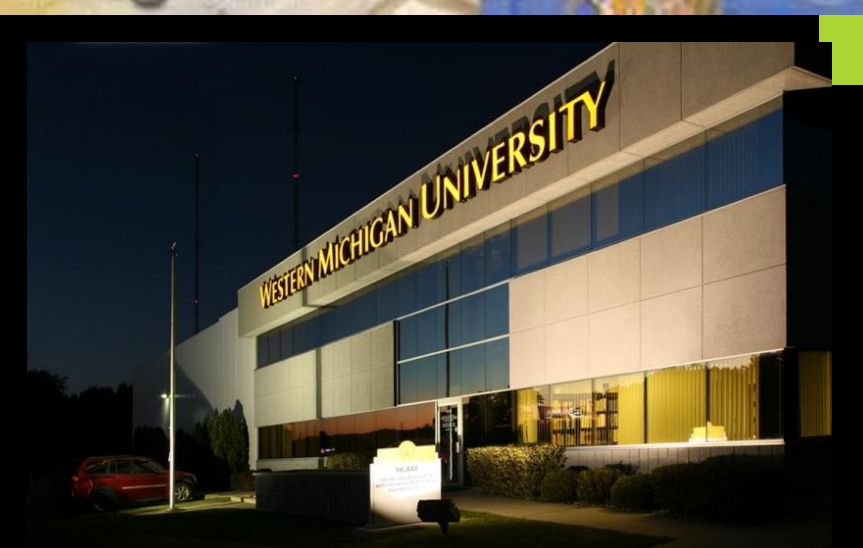

Real geologists from Western Michigan University who talk to students and answer their questions

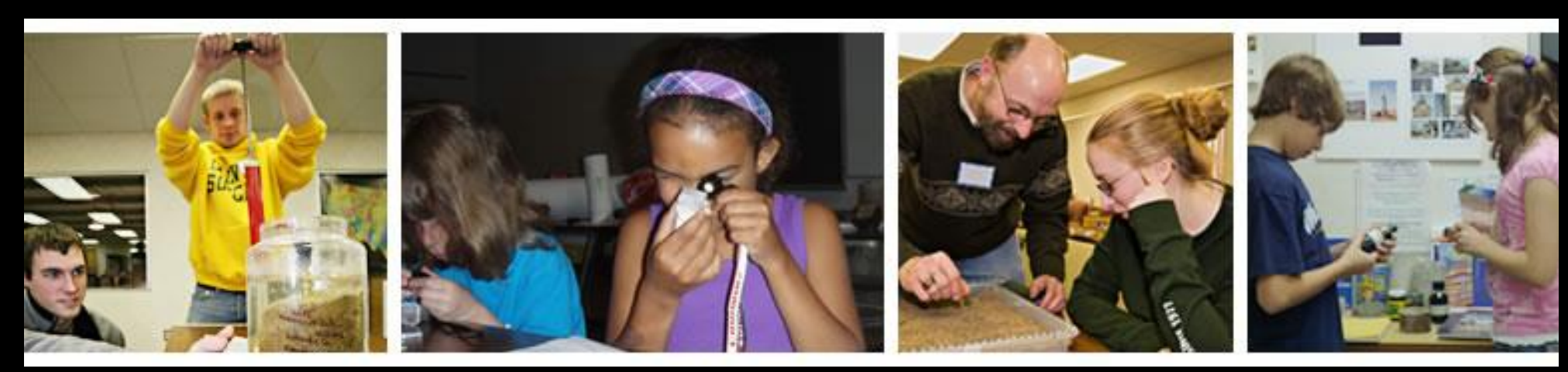

Website with lesson plans and other resources for teachers, students and parents www.wmich.edu/corekids 


\section{Dinosaur Park - lessons learned}

- Ensure community buy-in - discussions with other departments sharing site (Physics, Math, Statistics and Lee Honors College)

- Work with University bureaucracy - Landscaping and facilities management, higher administration in college (critical groups to have on board)

- A lot of planning - site access, landscaping, campus planning, financing projects, etc.

Everything is much more expensive than planned!

L Lighting

- Security (Cameras)

- Future landscaping costs - how to keep site low maintenance

- Large sculptures - difficult to find space big enough for storage 


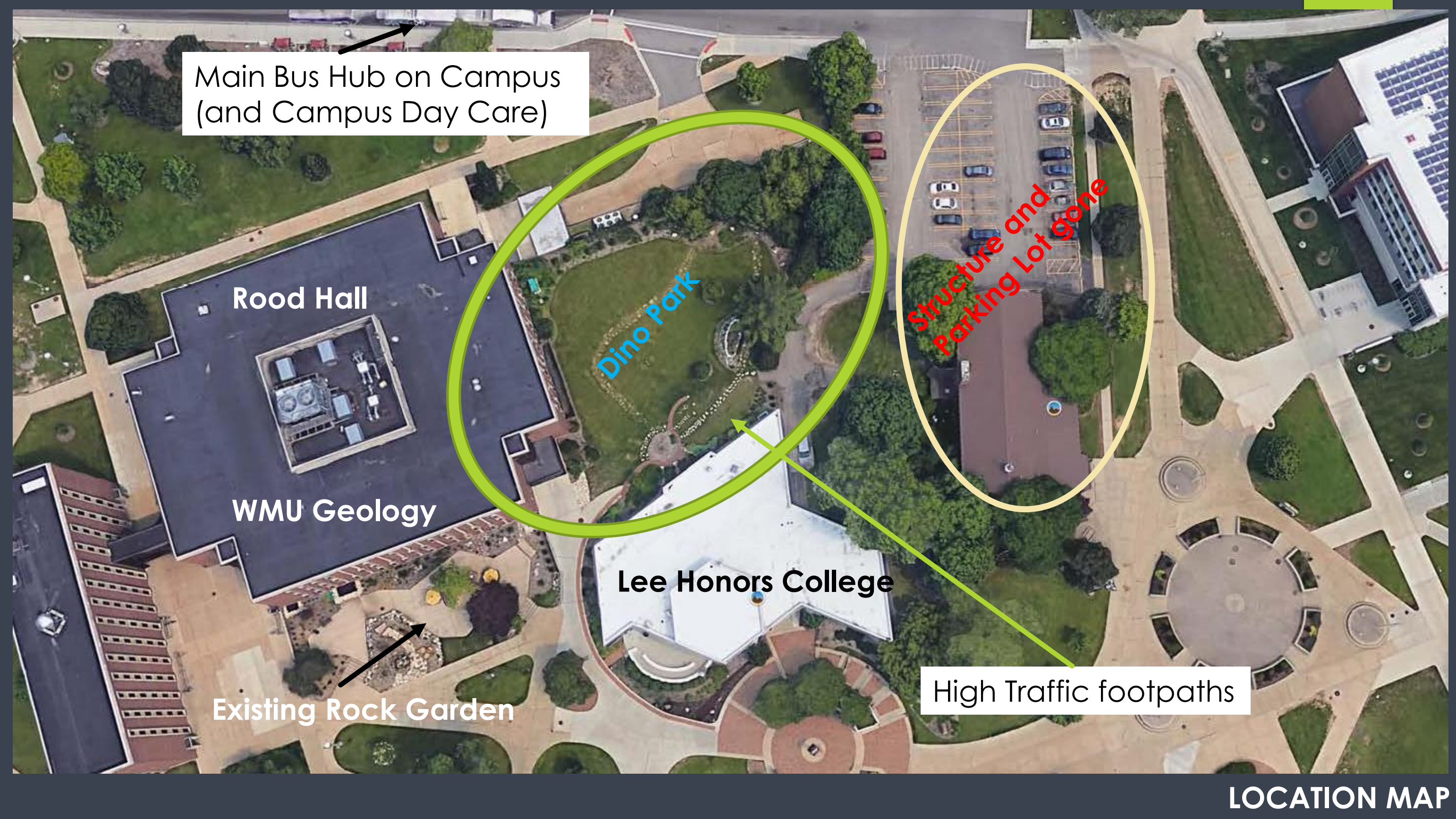




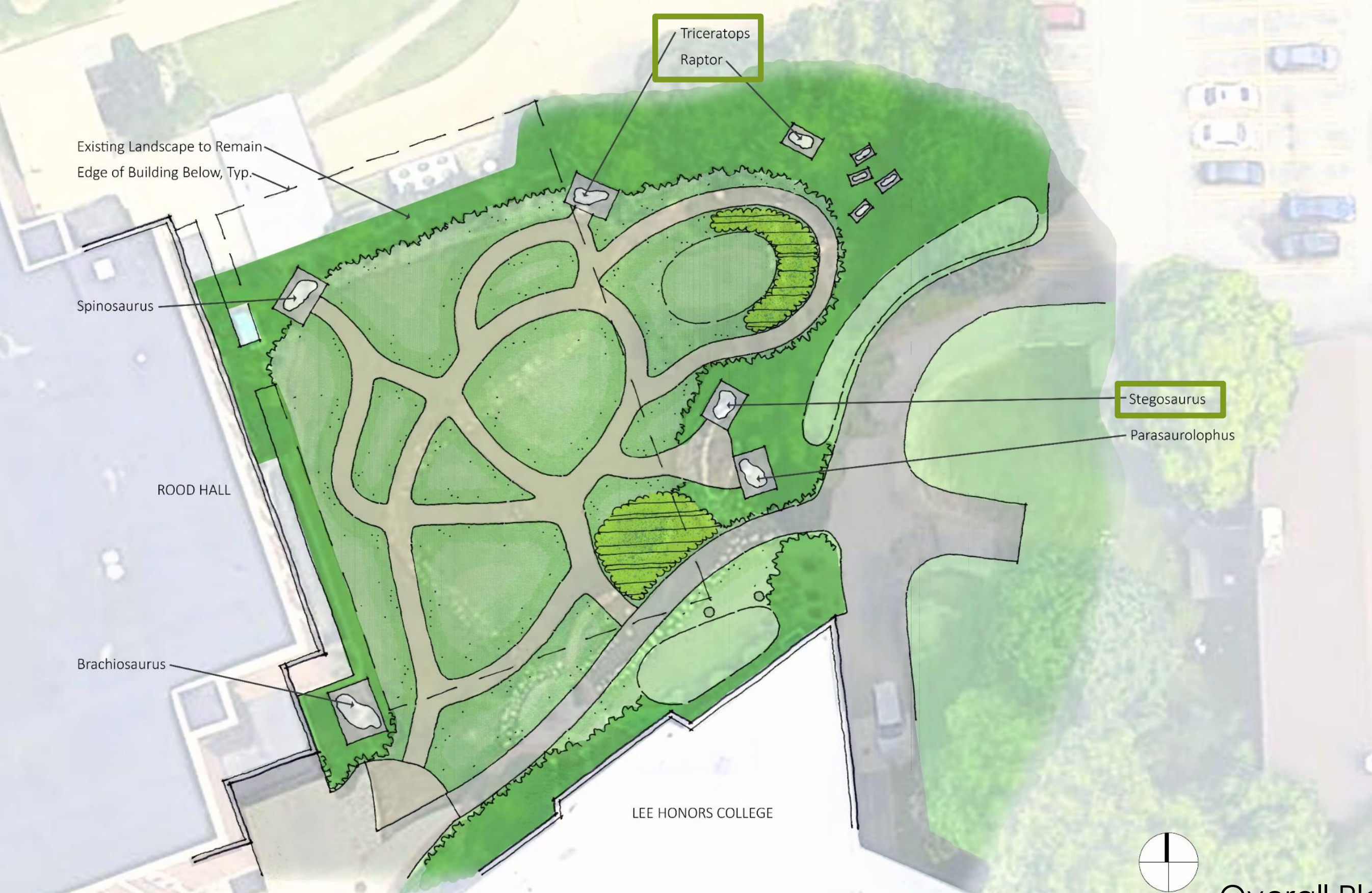

Currently have a few dinosaurs installed - will be moving into Phase I hopefully this summer 


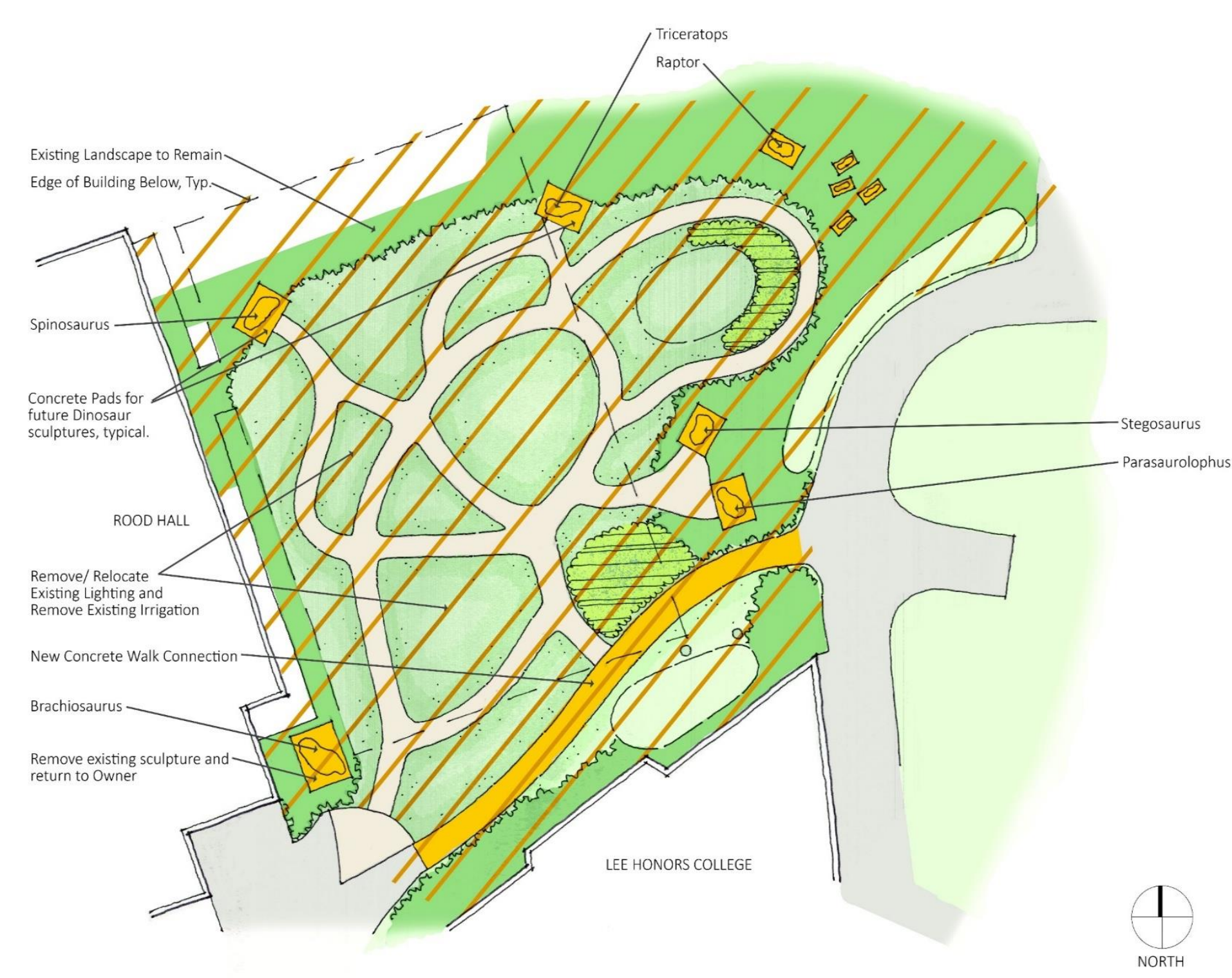

Phase l:

1) Remove/relocate existing exterior lighting as needed for proposed work.

2) Remove existing sprinkler heads and reinstall new heads for new proposed work.

3) Install new concrete sidewalk at existing walking path between Sangren Hall and Rood Hall.

4) Install concrete pads for future dinosaur sculptures. (cost-savings measure)

>5) Install conduit under all proposed paths for future lighting and irrigation work.

b) Relocate existing copper boulder to parking-lot entrance of Rood Hall. 


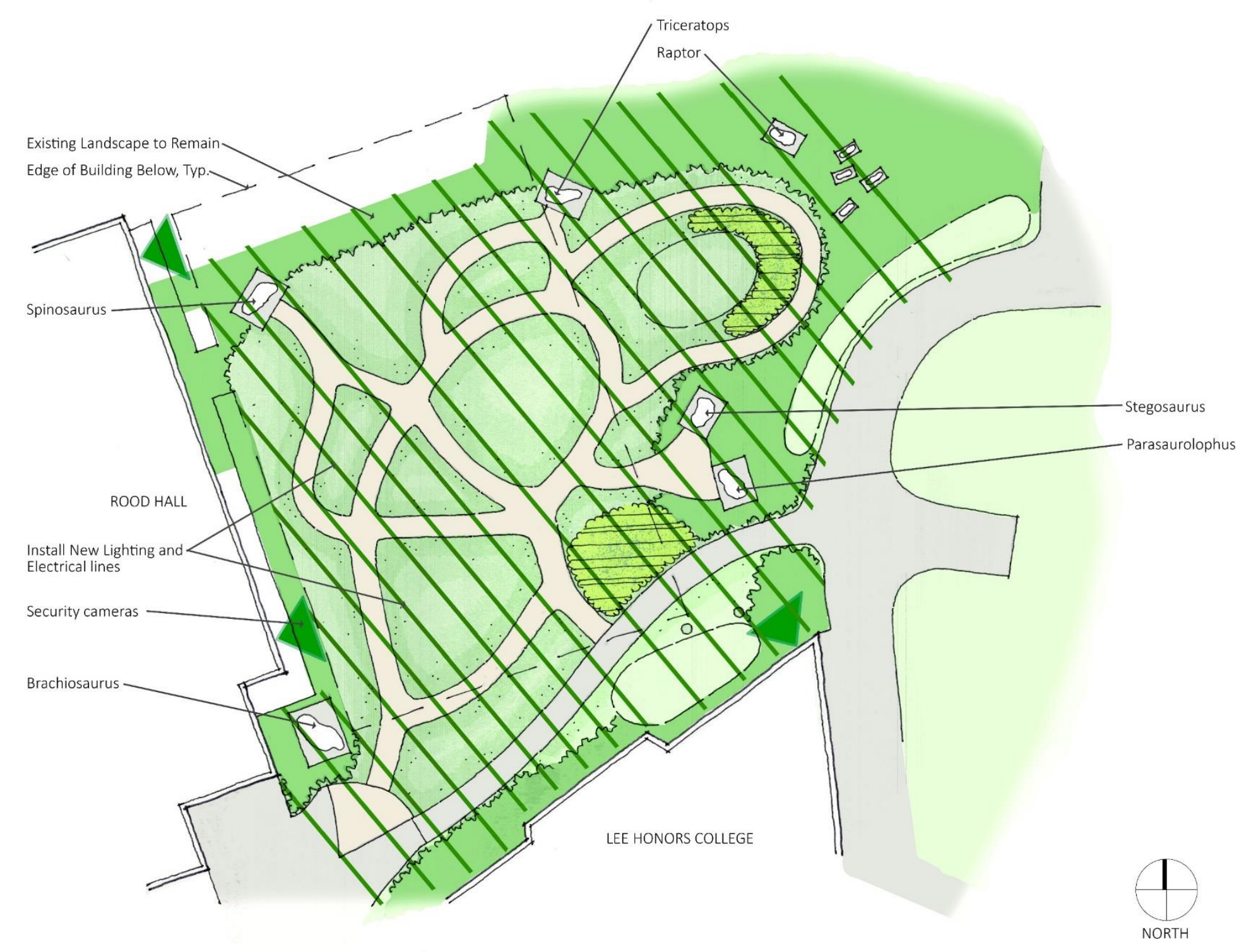

\section{Phase ll:}

1) Install new lighting and electrical lines for security and

highlighting dinosaur sculptures.

2) Install security cameras/system. 


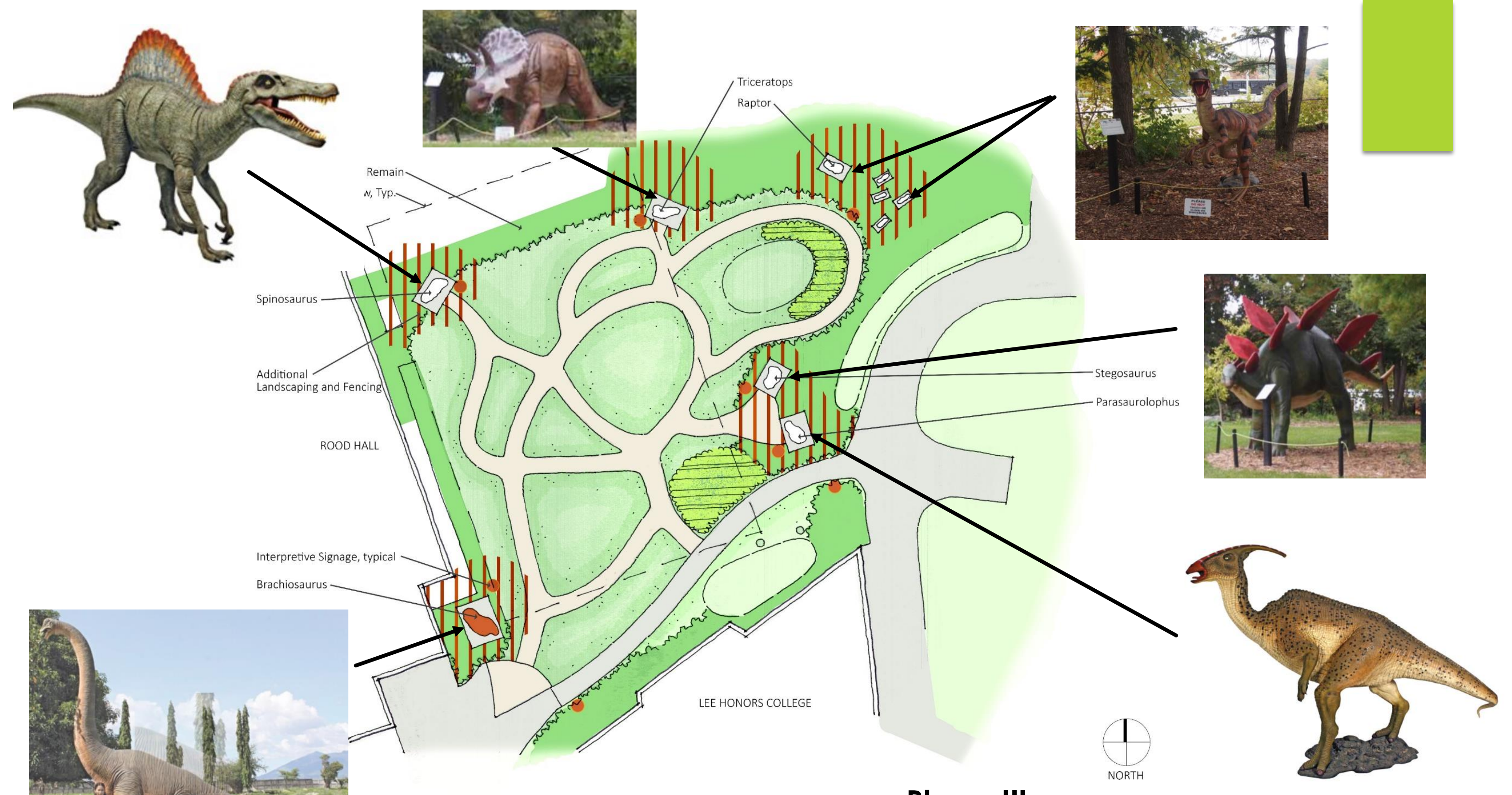

Phase III

Remove existing topsoil/sod - Install new aggregate paths, new topsoil and plantings, Reshape topography for rain gardens 


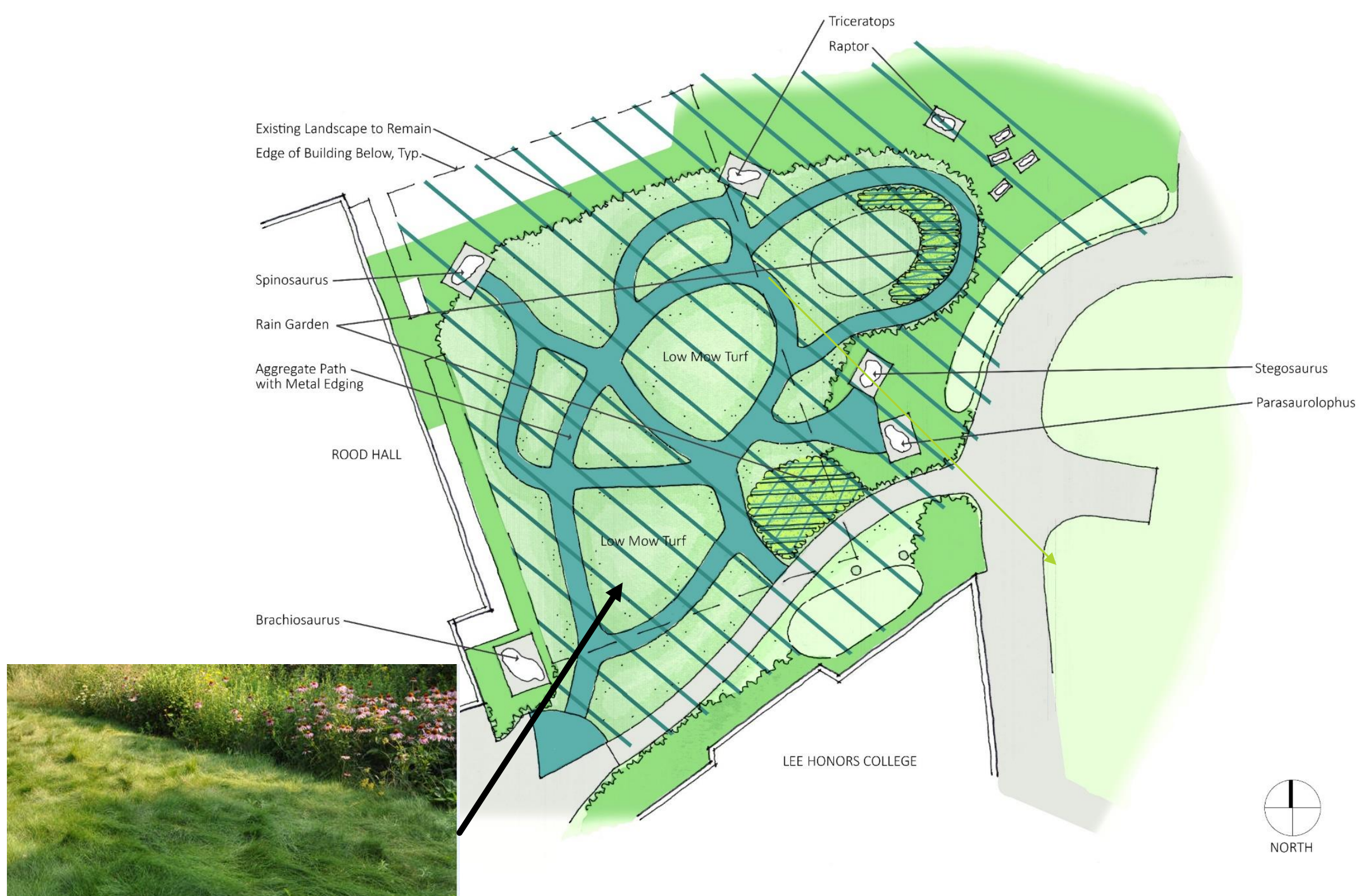




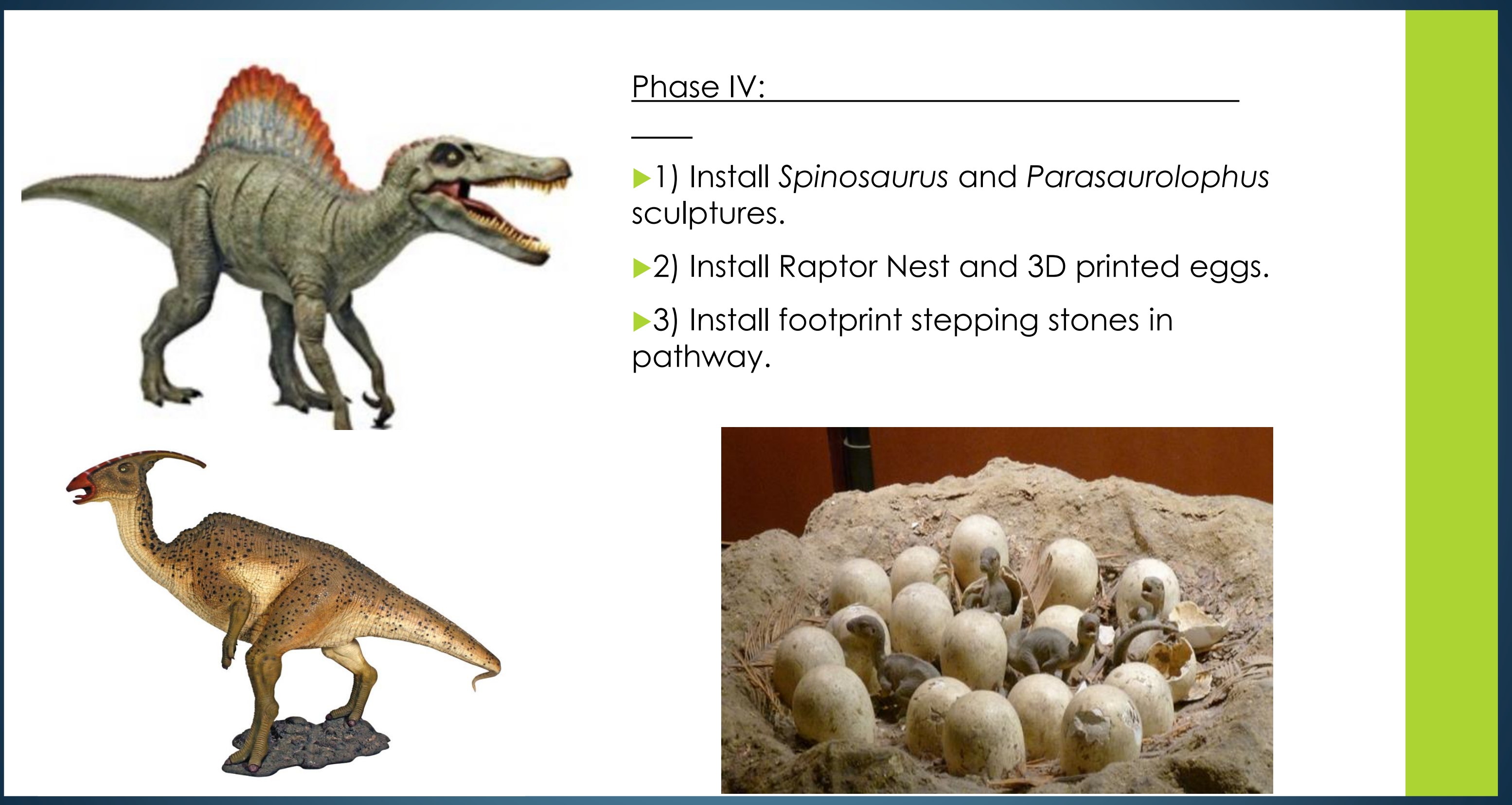




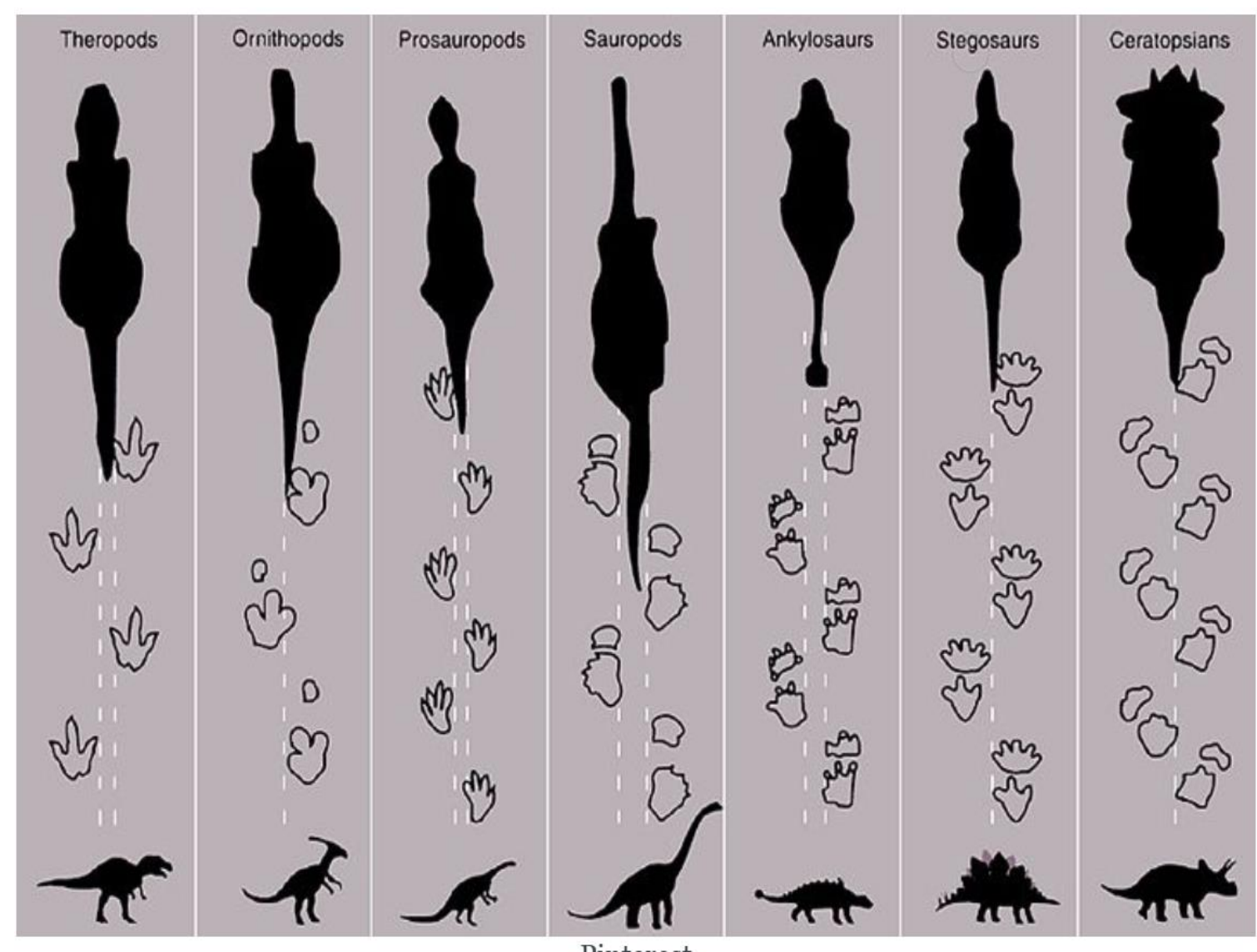

Phase IV:

1) Install Spinosaurus and Parasaurolophus sculptures.

2) Install Raptor Nest and 3D printed eggs.

3) Install footprint stepping stones in pathway. 


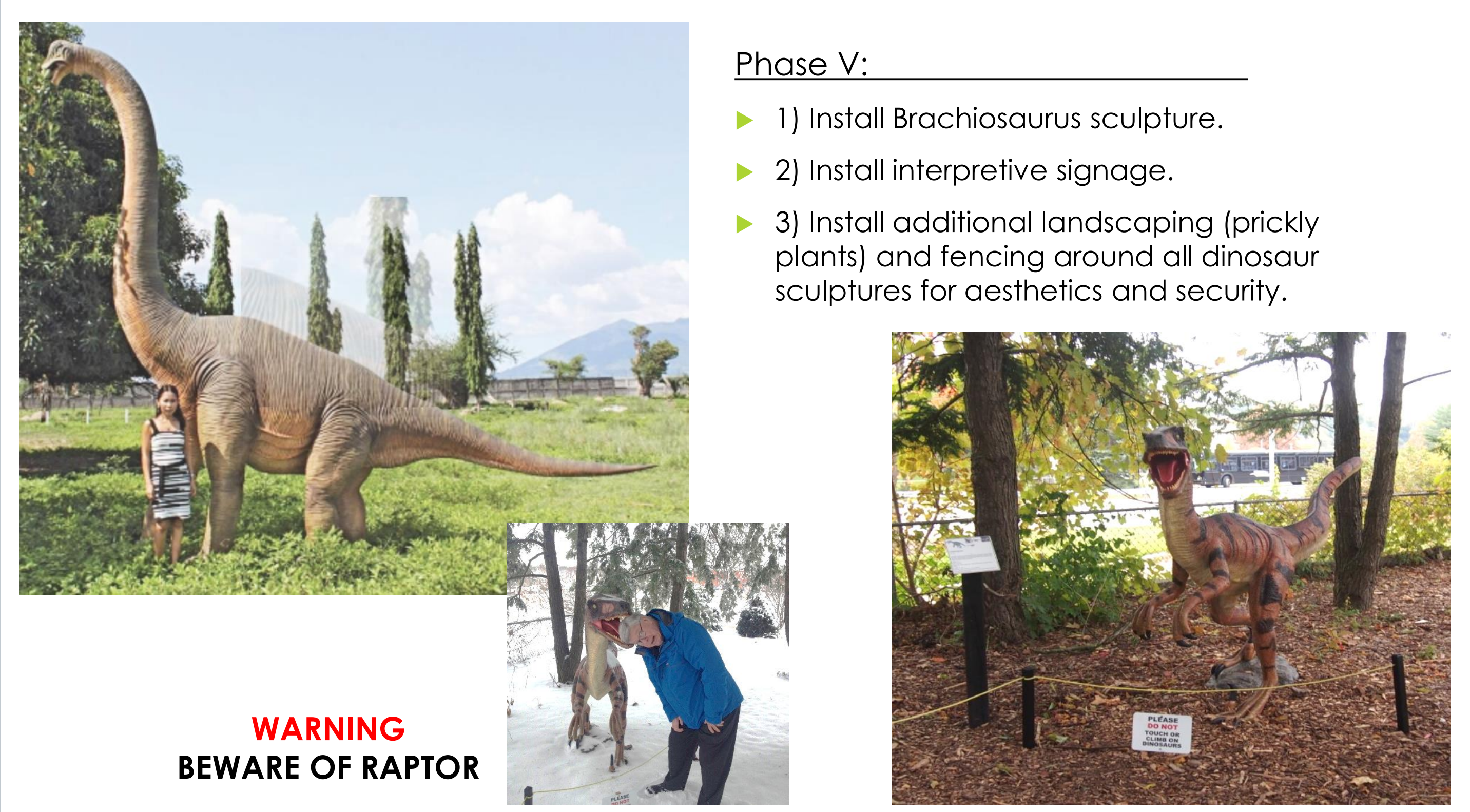




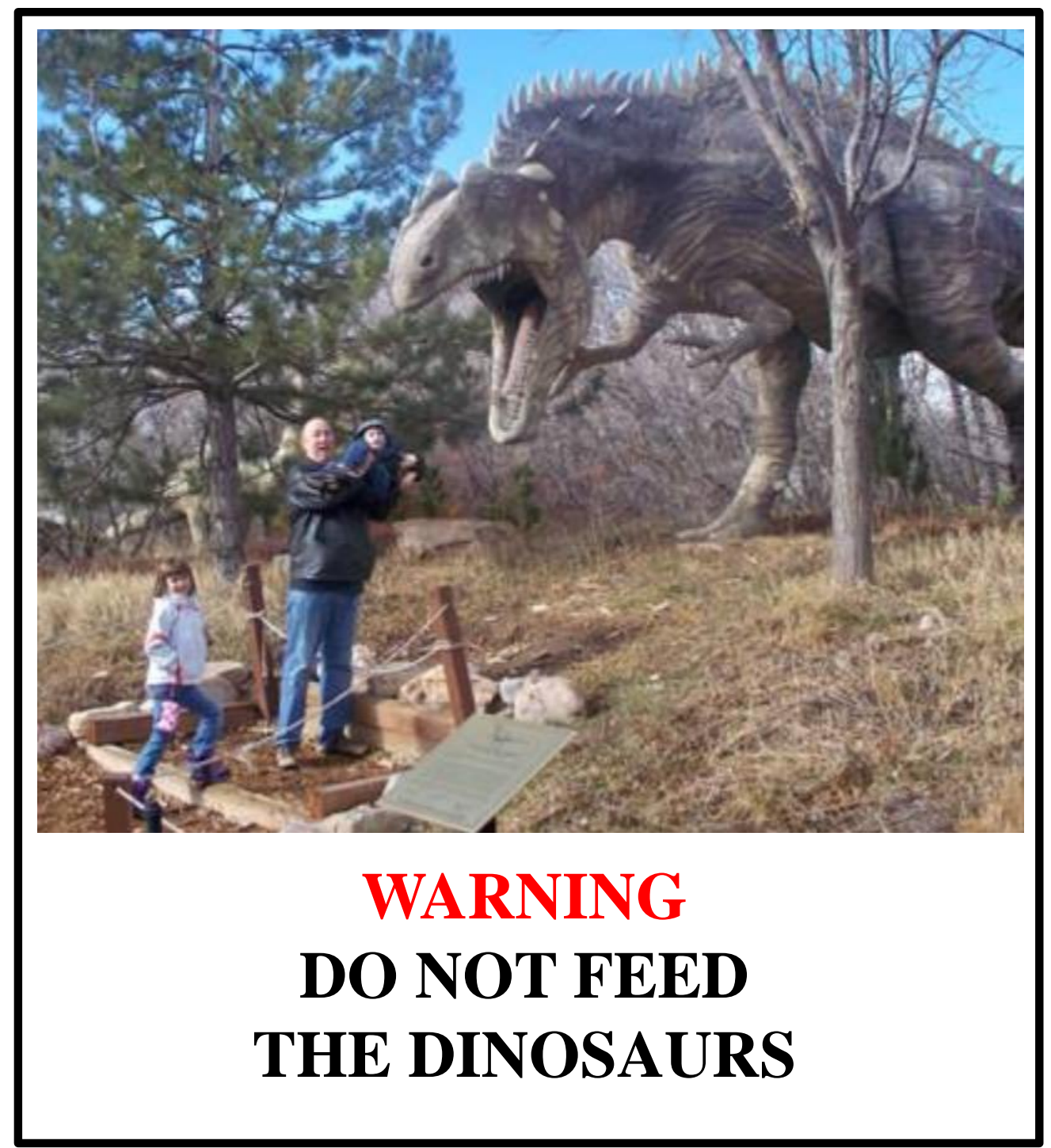

\section{SIGNAGE}

Western Michigan University College of Arts and Sciences

Department of

Geological and Environmental Sciences

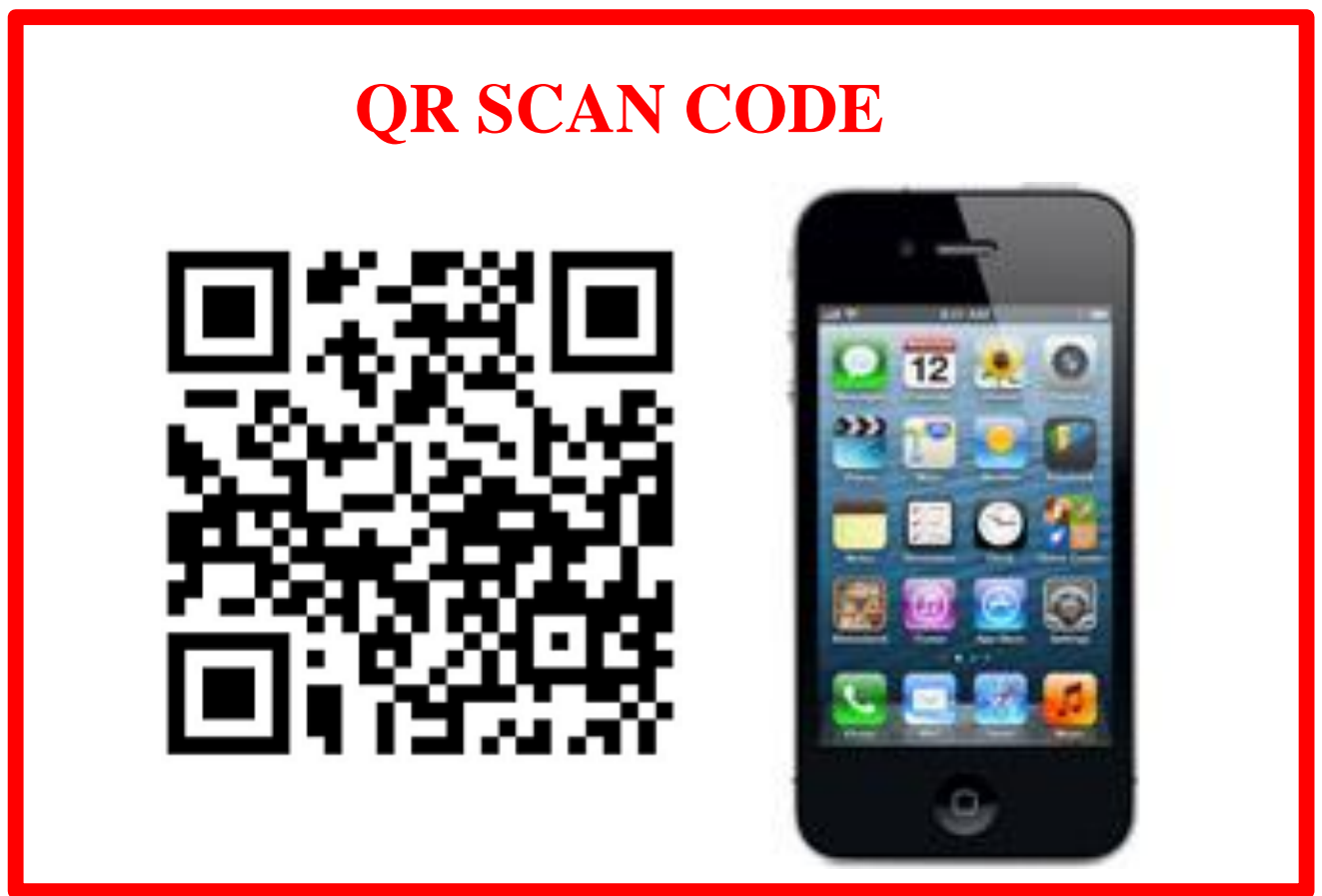

The Importance of Signage 


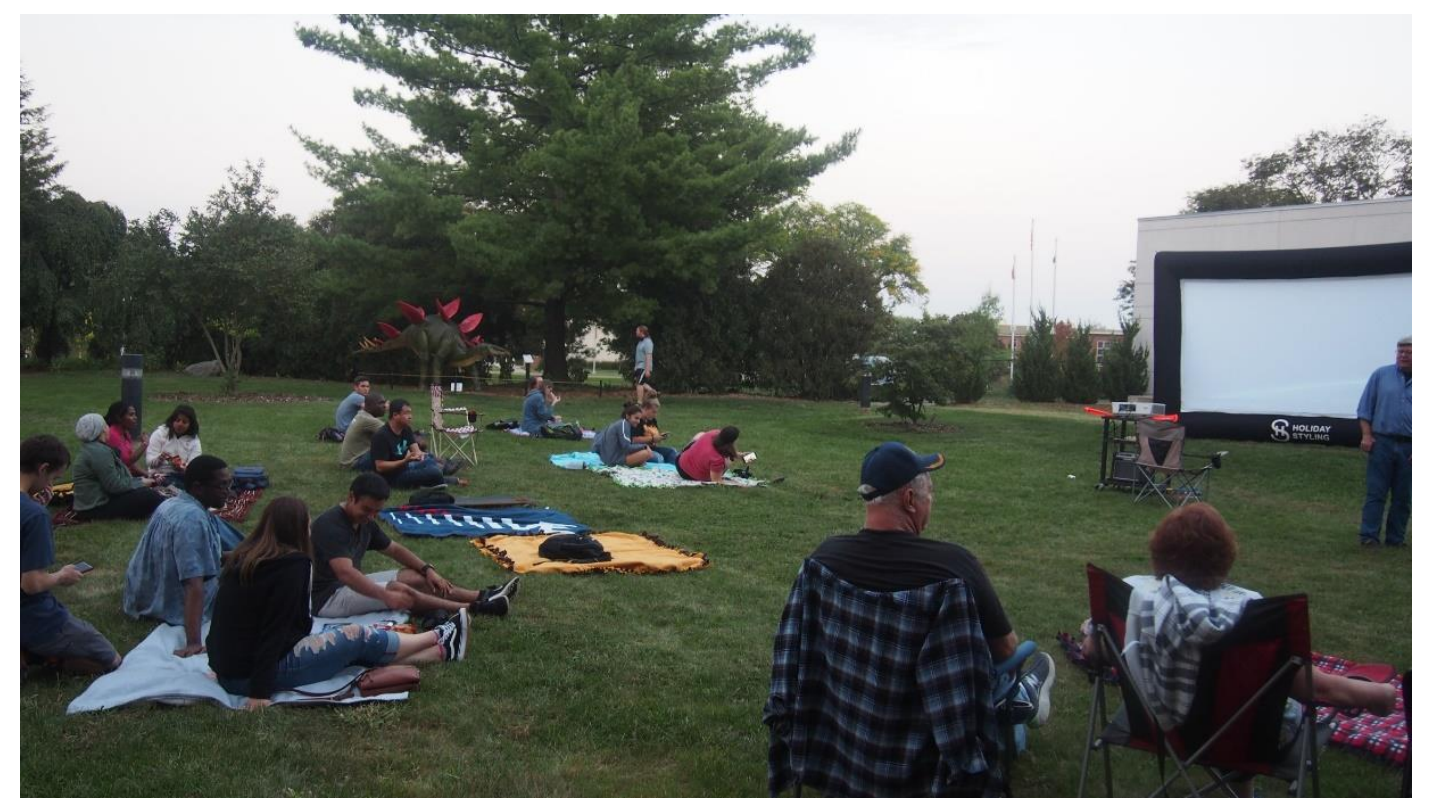

We did not do "Dinner in an Iguanodon" but instead - "Movies with a Stegosaur"

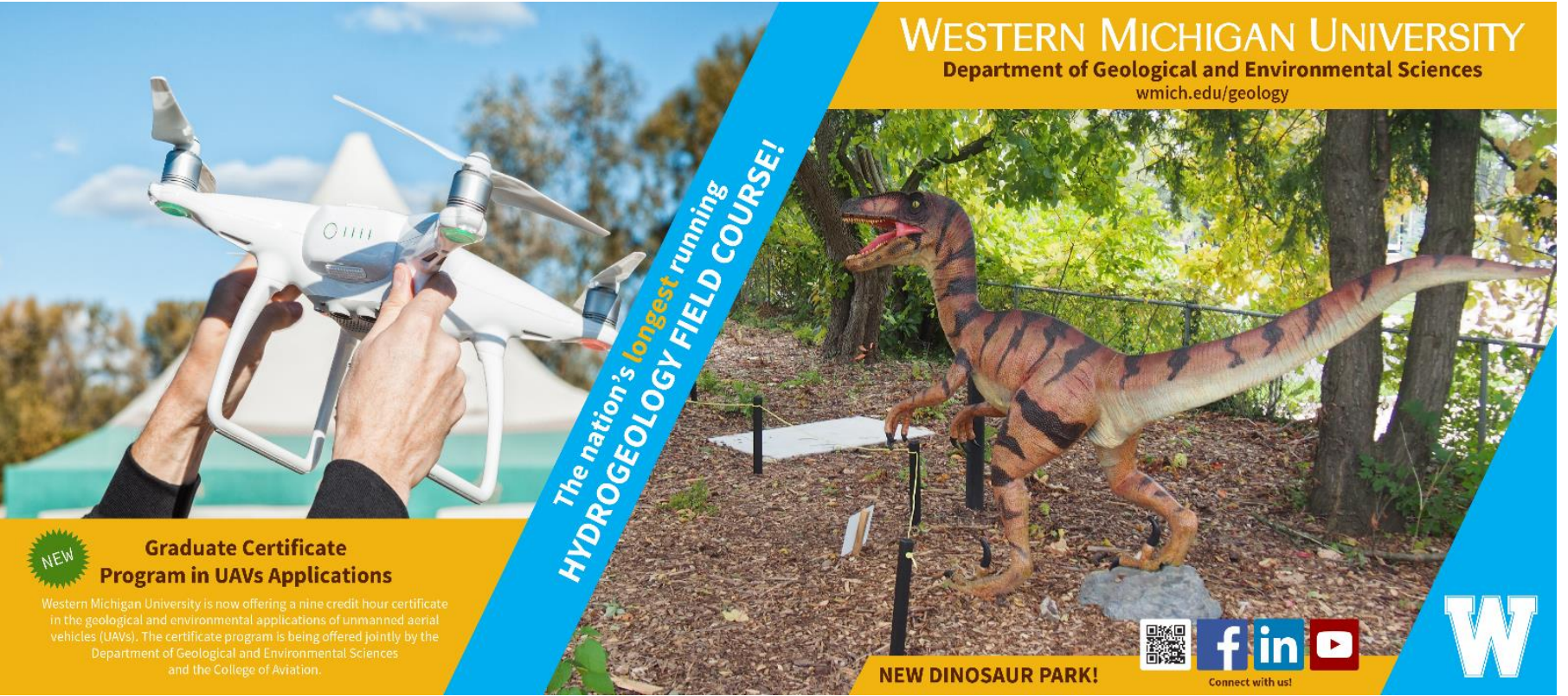

\section{Promotional Materials}

2018 Department Newsletter

Department Booth at National GSA 2018

Jurassic World 2 Movie Night with the Dinosaurs
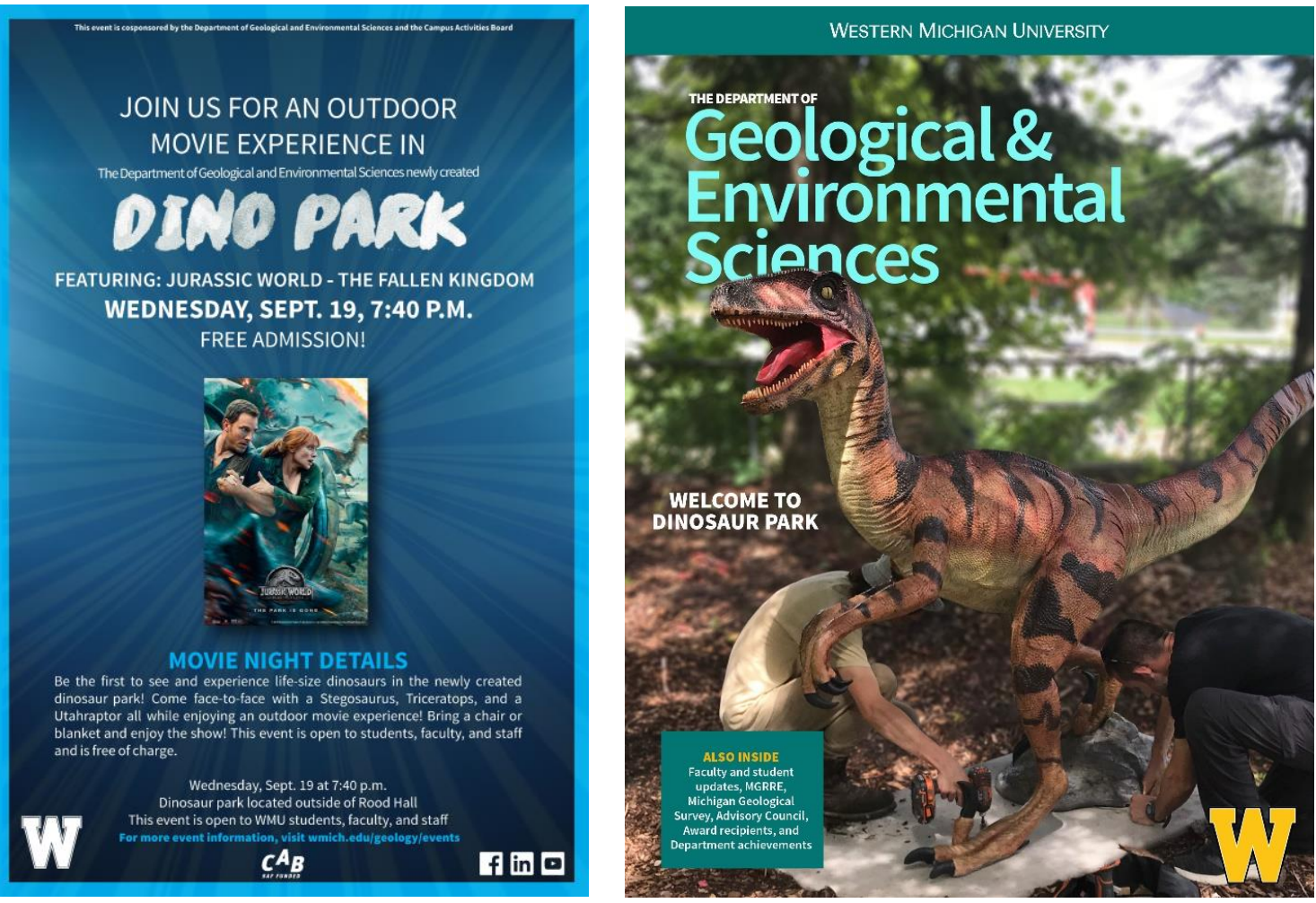


\section{Conclusions}

- Fun way to increase visibility of Geological and Environmental Sciences to the rest of campus

- Provide alternate facility to Museum to enhance on-campus outreach (summer camps, daily visitors)

- Required much leg-work - had to have department approval, followed by several administrative units on campus

- Funding challenges - donations, student course fees, other department funds

- Part of long-term rejuvenation of the Lloyd Schmaltz Geological Museum 

the following people:

\section{Rachel Hughes-Nilsson}

O’Boyle, Cowell, Blalock \& Assoc., Inc.

350 E. Michigan Avenue, Ste 415, Kalamazoo, Ml 49007

1048 Wealthy Street SE, Grand Rapids, MI 49506

O (269) 381-3357

M (269) 760-2142

\section{ocba}

WESTERN MICHIGAN UNIVERSITY
Facilities Management

Drs. Mohamed Sultan, Carla Koretsky and Heather Petcovic

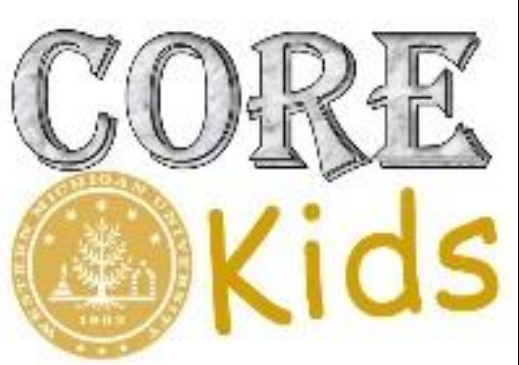

\section{Our second Utahraptor}

Currently hanging out in our Minerals and Rocks Lab room with the students until spring! 
